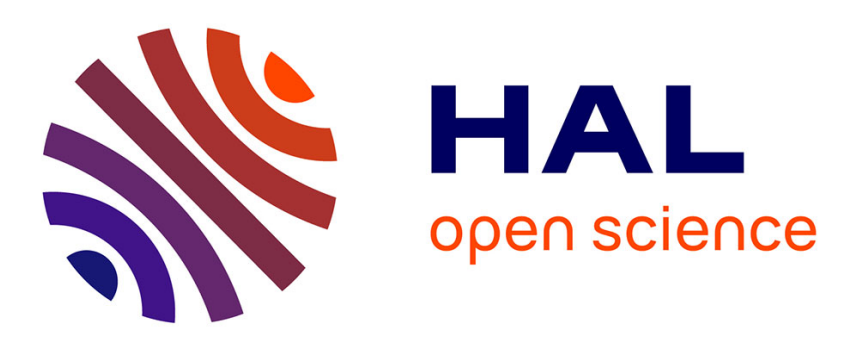

\title{
IMU/LIDAR based positioning of a gangway for maintenance operations on wind farms
}

Pierre Merriaux, Rémi Boutteau, Pascal Vasseur, Xavier Savatier

\section{To cite this version:}

Pierre Merriaux, Rémi Boutteau, Pascal Vasseur, Xavier Savatier. IMU/LIDAR based positioning of a gangway for maintenance operations on wind farms. 2014 IEEE/RSJ International Conference on Intelligent Robots and Systems (IROS 2014), Sep 2014, Chicago, United States. 10.1109/IROS.2014.6943156 . hal-01710416

\section{HAL Id: hal-01710416 https://hal.science/hal-01710416}

Submitted on 15 Feb 2018

HAL is a multi-disciplinary open access archive for the deposit and dissemination of scientific research documents, whether they are published or not. The documents may come from teaching and research institutions in France or abroad, or from public or private research centers.
L'archive ouverte pluridisciplinaire HAL, est destinée au dépôt et à la diffusion de documents scientifiques de niveau recherche, publiés ou non, émanant des établissements d'enseignement et de recherche français ou étrangers, des laboratoires publics ou privés. 


\title{
IMU/LIDAR based positioning of a gangway for maintenance operations on wind farms
}

\author{
P. Merriaux \\ R. Boutteau \\ P. Vasseur \\ X. Savatier
}

\begin{abstract}
This article studies the feasibility of an exteroceptive system for the contactless control of a motioncompensated gangway which can be used for maintenance operations on offshore wind farms. Our study shows that current systems based only on inertial systems are not accurate enough to ensure the gangway is held in place without being secured mechanically. Using measurements from a 2D LIDAR system, we propose a method for the real-time monitoring of the position of the gangway in relation to the offshore wind turbine. Our algorithm involves detecting and estimating the position of the wind turbine pile in a 2D scatter diagram using robust approaches. To evaluate our method, we have installed a realtime 3D simulation chain fed with data from actual measurements. We obtain a measurement accuracy of the order of a centimeter, in real time, in representative sea state scenarios.
\end{abstract}

\section{INTRODUCTION}

The objectives of the European Union for bringing the proportion of electricity produced by renewable energies to $23 \%$ have led to a sharp increase in activity in this area and particularly in production by offshore wind farms. By 2012, more than 1,500 wind turbines had already been deployed in 55 offshore wind farms, mainly in the North Sea and the Atlantic[17]. The economic constraints associated with the deployment of wind farms (high investment, regulation of electricity tariffs) require a very high level of operational availability which assumes an ability to carry out work quickly and in all weathers, either by air (helicopter), or by sea (ship). The latter solution is the most economical but gives rise to safety issues for maintenance operators who are often not hardened to carrying out work at sea. Thus, more and more so-called "motion-compensated" gangways are being developed for carrying out transshipment operations between the ship and the wind turbine from a stabilised platform. The most well-known of these is that by Ampelmann [1] designed on a hexapod base.

Other solutions exist or are being developed based on turret and telescopic ladder type structures [2][3][5][6] or cradles with poly-articulated arms [4]. With the exception of

P. Merriaux, R. Boutteau and X. Savatier S., are with IRSEEM (Embedded Electronic Systems Research Institute)

P. Vasseur is with LITIS (Laboratory of Computing, Information Processing and Systems) solution [4], all these systems need to be mechanically secured to a device which has to be permanently installed on the wind turbine.

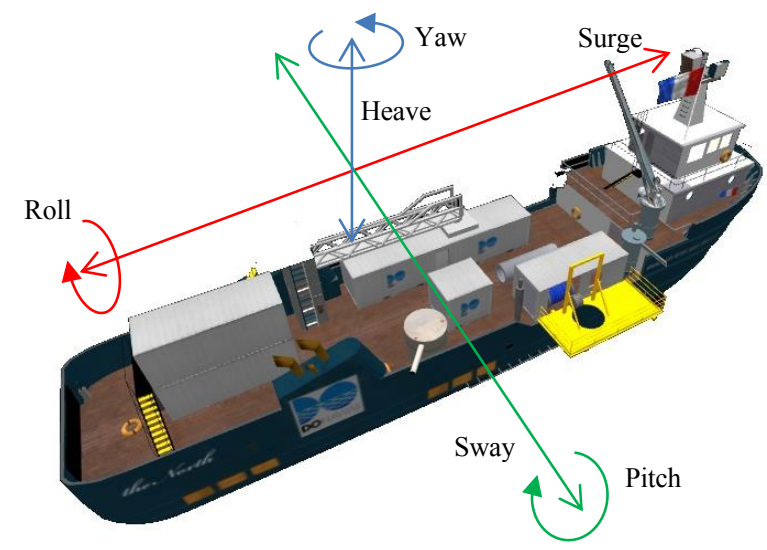

Figure 1 Axes and angles used in this study

This restriction makes it difficult to release the gangway quickly in the event of a problem and requires the ship to be held in an accurate position relative to the wind turbine. In this article, we propose to study the feasibility of a contactless coupling solution based on an inertial measurement of the ship's movement coupled with a measurement by laser telemetry.

\section{PERCEPTION CHAIN FOR CONTACTLESS COMPENSATION OF THE MOTION OF A GANGWAY}

\section{A. System analysis}

The motion-compensated gangway can be viewed as mechatronic system installed on board the ship and whose function is to counter react to the movements arising from the combined effects of swell, current and wind. Actually, most of the ships which are to receive this type of gangway are equipped with a dynamic positioning system (DP) whose performance now enables a single-hulled ship of less than $100 \mathrm{~m}$ length to be held in an ellipse of 1 to $1.5 \mathrm{~m}$. However, the movements compensated by the DP are only the translations, i.e. surge and sway (Figure 1).

The figure below (Figure 2) shows the main functional blocks of a motion-compensated gangway. One of the key factors in the performance of such a system is the perception 
subsystem. Currently, most solutions use inertial systems (IMU).

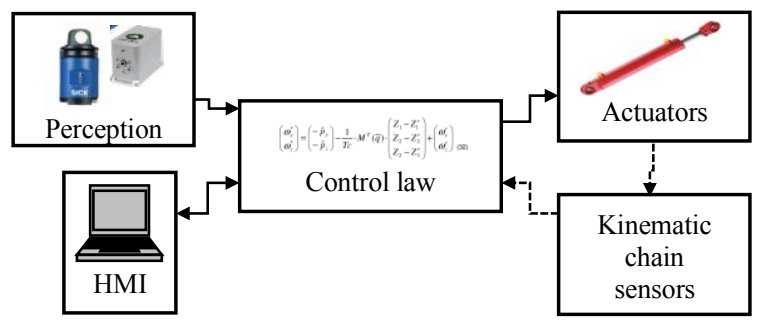

Figure 2 Diagram of a compensated gangway system

As we will show in the rest of this article, all marinequalified inertial systems on the market show errors in translation and rotation measurements. For a gangway which is not mechanically secured, this results in positioning errors of the end of the gangway which cannot be corrected without knowing the distance between the gangway and the wind turbine access area. Thus, a secured positioning of the gangway will require a closed-loop control scheme based on a robust distance measuring device. To determine the performance required for a distance measuring system installed on the gangway, it is then necessary to evaluate the performances which can be obtained with marine-qualified inertial systems using current technologies.

B. Comparative study of the performance of inertial systems qualified for use with marine applications

To objectively assess the performance which can be obtained with the inertial systems currently used for marine applications, we have compared the performance of three units representative of the various technologies (MEMS, FOG). These tests were carried out in collaboration with Ifremer-Brest [14]. A study of the seakeeping qualities of a hull 50 metres in length has provided the actual movements that a ship undergoes. The sea states used in this study are representative of those encountered with the offshore wind farms currently deployed in the North Sea (Figure 4). These movements were then applied to a hexapod (Figure 5) on which the three inertial systems under test had been installed. It must be emphasized that the processing principle installed in the marine inertial systems did not enable the surge displacement and sway to be measured. The errors in the angle and heave displacement measurements are shown in TABLE I. For a gangway with a span of $20 \mathrm{~m}$, these represent distance errors of $8.5 \mathrm{~cm}$ for a FOG unit and nearly $30 \mathrm{~cm}$ for the MEMS units. To this error must be added that of the ship's dynamic positioning system (DP) which could not be measured with the inertial system.

TABLE I STANDARD DEVIATION ( 1 s) BETWEEN THE REFERENCE POSITION OF THE HEXAPOD AND THE DATA FROM THE INERTIAL SYSTEMS

\begin{tabular}{|c|c|c|c|}
\hline & IMU 1 & IMU 2 & IMU 3 \\
\hline Roll $\left(^{\circ}\right)$ & $6.41510^{-3}$ & $36.6910^{-3}$ & $42.2410^{-3}$ \\
\hline Pitch $\left(^{\circ}\right)$ & $7.96810^{-3}$ & $34.5910^{-3}$ & $34.5310^{-3}$ \\
\hline Yaw $\left(^{\circ}\right)$ & $9.97210^{-3}$ & 2.817 & 23.803 \\
\hline Heave $(\mathrm{m})$ & $1.25110^{-2}$ & $2.28510^{-2}$ & $3.25510^{-2}$ \\
\hline
\end{tabular}

In conclusion, these tests confirm that the heave, pitch and roll are provided accurately by the IMU. Nevertheless, it is necessary to add a perception device at the end of the gangway to estimate surge, sway and yaw.

\section{Solutions for telemetry at the end of the gangway}

We are aiming to define an exteroceptive sensor which, placed at the end of the gangway, will supplement the data provided by the inertial system with a measurement of the horizontal translations and if necessary the yaw. All of these measurements will be used by an information and control system responsible for the servoing of the gangway position. This model is similar to a sensor referenced control problem and has been comprehensively treated for the case of visual servoing[15][16]. For this application and in spite of its cost advantages, the use of a robotic vision system does not appear to be a viable solution. Indeed, as can be seen on the central picture in Figure 3, a wind turbine pile has very little texture and is subject to fouling and contamination from the marine environment.
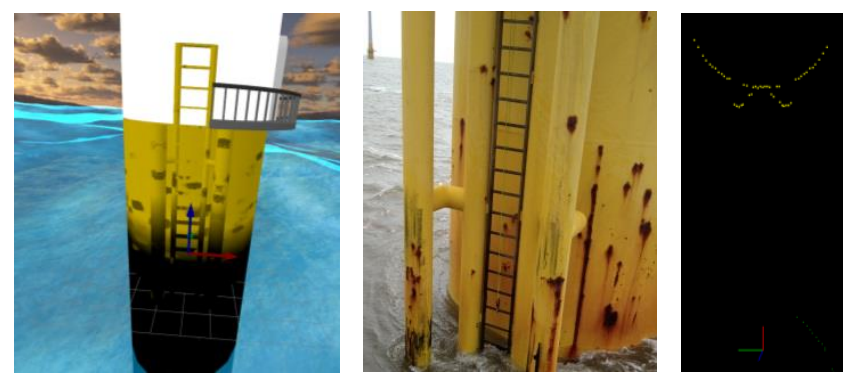

Figure 3 Wind turbine pile - simulated, actual and LIDAR sheet obtained

The tests we have carried out in simulation mode on the traditional robotic vision-based methods have not provided conclusive results. Another solution consists of using an infra-red triangulation system such as [7]. This system is used to measure sway when craning containers in ports and is therefore fully suited to use in a maritime environment. In addition, the measurement performance $\left(<0.02^{\circ}\right.$ i.e. $1 \mathrm{~mm}$ at $5 \mathrm{~m})$ is compatible with our application. However, the use of such a solution would require all wind turbines to be fitted with active infra-red beacons and which, in addition, have to be powered.

A 1D laser telemetry solution such as [8] would enable the two translations to be measured, but it would be necessary to align the end of the gangway with the wind turbine tube. The solution we have finally chosen is based on a 2D LIDAR. These systems are widely used for industrial applications in outdoor environments and under difficult conditions. The latest developments based on multi-echo methods overcome the problems of water droplets and spray making it possible to use them in operations where safety is paramount such as in crane operations in port [18]. An algorithm must therefore be developed which would extract the position of the wind turbine tube from the 2D LIDAR data while guaranteeing an accuracy and a response time compatible with our instrumentation and control algorithms. 

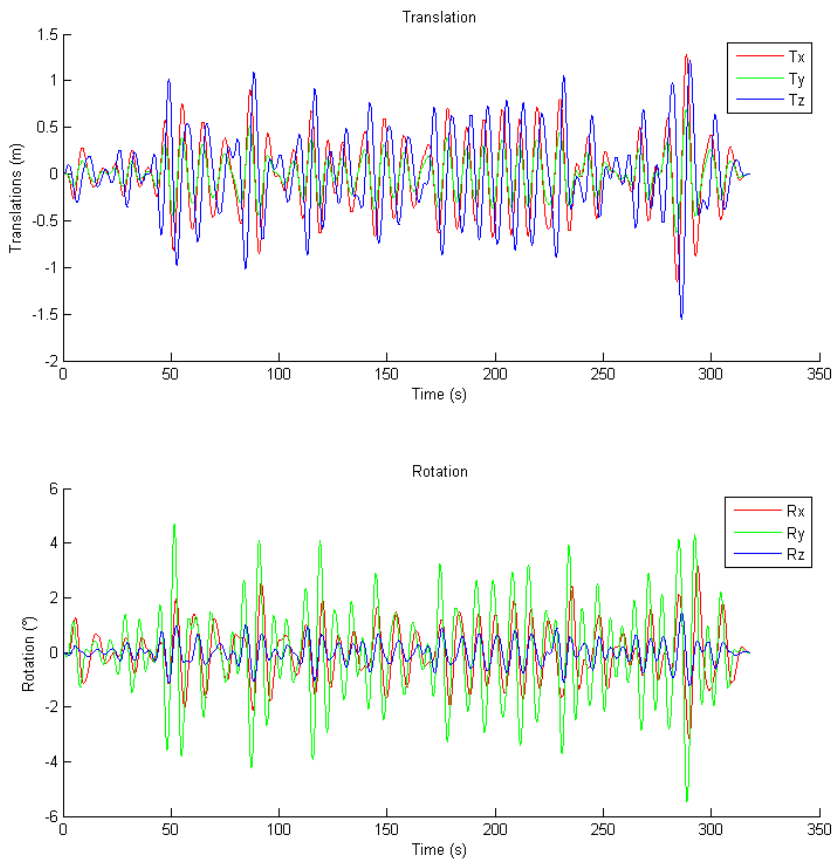

Figure 4 Movement of ship $\mathrm{Hs}=2.5 \mathrm{~m}$ (specific swell height), Tps $=9 \mathrm{~s}$ (swell period), $210^{\circ}$ (angle formed between the hull and the swell)

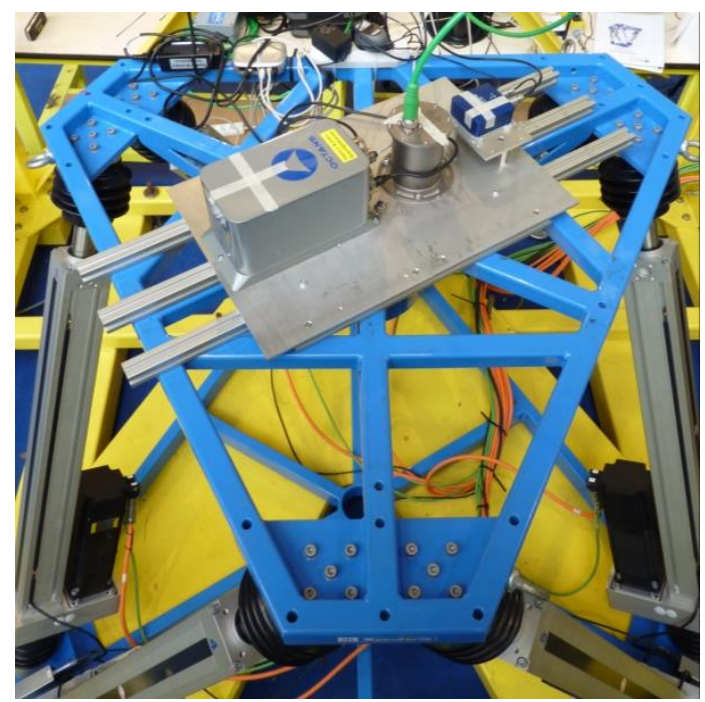

Figure 5 Hexapod used to evaluate the performance of the inertial systems at IFREMER Brest

\section{PROPOSED METHOD}

\section{A. Mechanical structure and perception system}

The study was carried out by considering a telescopic gangway with $20 \mathrm{~m}$ span. This structure can be considered as an RRP serial kinematic chain (Figure 6). We use modified Denavit-Hartenberg parameters to determine the model and the inverse Jacobian matrix [19] :

$$
J=\left[\begin{array}{ccc}
-\sin \left(Q_{1}\right) \cos \left(Q_{2}\right) Q_{3} & \cos \left(Q_{1}\right) \sin \left(Q_{2}\right) Q_{3} & \cos \left(Q_{1}\right) \cos \left(Q_{2}\right) \\
\cos \left(Q_{1}\right) \cos \left(Q_{2}\right) Q_{3} & -\sin \left(Q_{1}\right) \sin \left(Q_{2}\right) Q_{3} & \sin \left(Q_{1}\right) \cos \left(Q_{2}\right) \\
0 & -\cos \left(Q_{2}\right) Q_{3} & -\sin \left(Q_{2}\right)
\end{array}\right]
$$

Sea conditions cause the ship to move in 6 degrees of freedom (Figure 4). The goal is to maintain the end of the gangway in front of point $\mathrm{P}_{\mathrm{t}}$. The inertial measurement unit measures a part of the information in the reference frame $R_{0}$, but it is not sufficient to solve the issue.

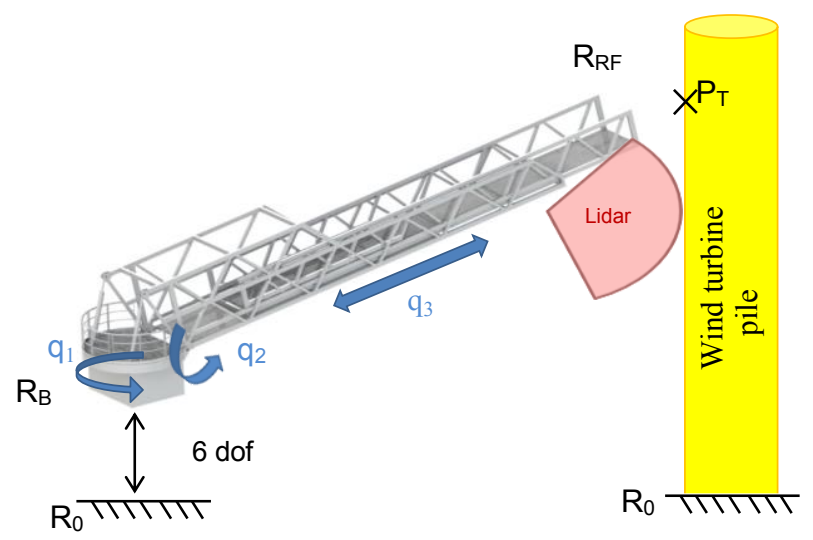

Figure 6 Gangway mechanics schematic

As explained, a closed loop position control (Figure 8) will require an additional measurement system in order to correct the horizontal ship translations. Therefore, we have considered a 2D LIDAR system installed at the end of the fixed span. This position is a compromise between the angular resolution of the LIDAR and the shadow areas generated by very close objects, such as marine fenders.

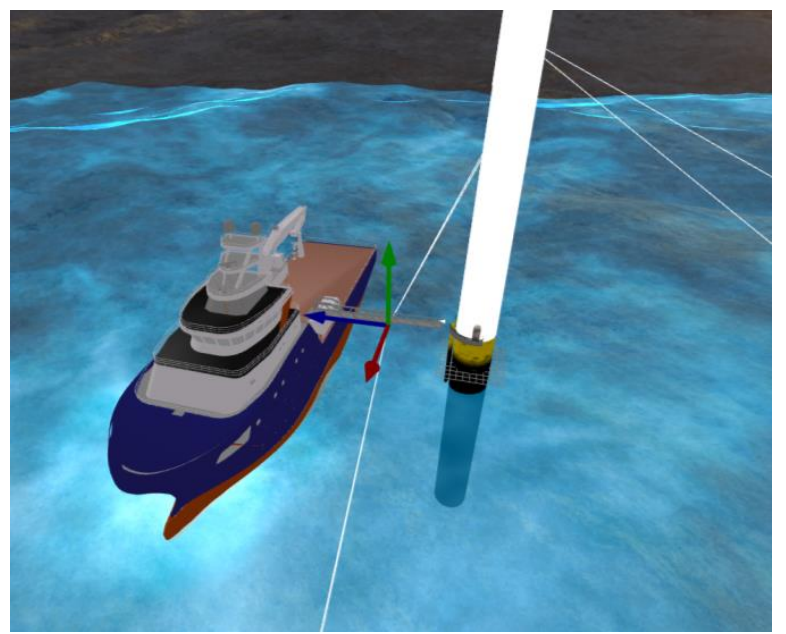

Figure 7 Position of the LIDAR on the gangway. The LIDAR is represented by the red-green-blue reference frame $(\mathrm{red}=\mathrm{X}$ axis, green $=\mathrm{Y}$ axis, blue $=Z$ axis)

With the data fusion between proprioceptive sensors, the LIDAR range finder and an IMU, we are able to compute the position of $P_{t}$ point. The position variations and the inverse Jacobian Matrix are used to determine actuator commands. 


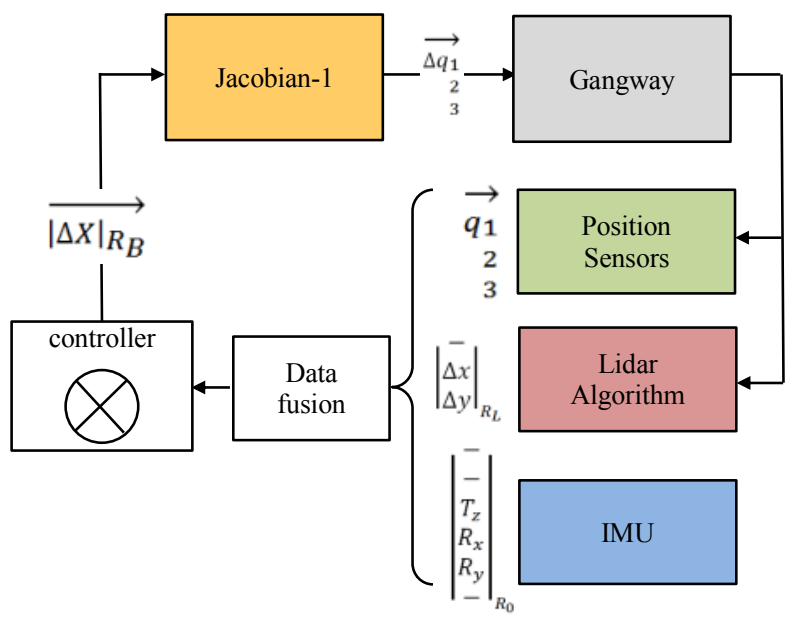

Figure 8 Simplified synoptic gangway control system

In the first step, the control only uses the IMU data. The DP residual movements can't be compensated, but with this first stabilization, it is possible for the range finder to lock on its target. In the second step, the LIDAR range finder algorithm provides us with the horizontal translation in the end of the gangway reference frame $\left(\mathrm{R}_{\mathrm{RF}}\right)$, to fully control the target position.

\section{B. Algorithm for estimating the position by LIDAR}

In this configuration, the laser sheet measures a horizontal cross-section of the wind turbine pile (anchored part of the mast). The relative position of the gangway relative to a fixed component of the wind turbine (ladder, disembarkation platform) can be calculated if the centre and diameter of the pile tube can be determined from the LIDAR measurement.

As the LIDAR measurements are contaminated with noise, a robust detection algorithm must be used. Initially, our approach consisted of detecting a circle associated with a Ransac type algorithm [13]: on each iteration, a circle equation is calculated from three points taken randomly. We keep the selection which has provided the largest number of scatter diagram points obtained by the LIDAR which confirm this hypothesis. This enables outlier points not belonging to the main tube of the wind turbine to be eliminated, like those for the ladder.

The parameters for the wind turbine circle (centre $C\left(x_{0}, y_{0}\right)$ and radius $r$ )) may be determined from three points using the following equations:

$$
\begin{aligned}
R^{2}= & \left(x-x_{0}\right)^{2}+\left(y-y_{0}\right)^{2} \\
& \text { Given } 3 \text { points }\left(x_{1}, y_{1}\right),\left(x_{2}, y_{2}\right) \text { et }\left(x_{3}, y_{3}\right) \\
a_{1}= & \left(y_{1}-y_{3}\right) /\left(x_{1}-x_{3}\right) \quad a_{2}=\left(y_{2}-y_{3}\right) /\left(x_{2}-x_{3}\right) \\
b_{1}= & \left(y_{1}+y_{3}\right) / 2+\frac{\left(x_{1}+x_{2}\right) / 2}{a_{1}} \\
b_{2}= & \left(y_{2}+y_{3}\right) / 2+\frac{\left(x_{2}+x_{2}\right) / 2}{a_{1}} \\
x_{0}= & \frac{\left(b_{2}-b_{1}\right)}{1 / a_{2}-1 / a_{1}} \quad y_{0}=\frac{-x}{a_{1}}+b_{1}
\end{aligned}
$$

$$
r=\sqrt{\left(x_{1}-x_{0}\right)^{2}+\left(y_{1}-y_{0}\right)^{2}}
$$

Once the circle equation which maximises the number of points considered as valid has been obtained, we apply a circular regression [10][12] to minimise the errors in the least squares sense.

To test this method, we generated a scatter diagram distributed randomly around a circle (radius $=1 \mathrm{~m}, \sigma=0.01 \mathrm{~m}$ ) in a simulation.

The initial tests showed that the method was highly sensitive depending on the distribution of the points. The points from the LIDAR are not distributed evenly around the circle but, as shown in Figure 3, on a quarter circle only. An error in estimating the radius directly increases the positioning error (Figure 9). To overcome this problem, we modified the circular regression algorithm to only estimate the centre. Indeed, as the radius is a constant, no longer continually estimating it increases the robustness of the algorithm.

TABLE II ERRORS BETWEEN THE ESTIMATED CENTRE OF THE CIRCLE OF THE WIND TURBINE PILE AND THE REFERENCE CENTRE WITH OR WITHOUT ESTIMATION OF THE RADIUS WITH POINTS OVER THE WHOLE OR A $1 / 4$ OF THE CIRCLE

\begin{tabular}{|c|c|c|}
\hline $\begin{array}{c}\text { Error }(\mathbf{m}) \\
\text { (for a radius of } 1 \mathrm{~m}, \\
100 \text { samples) }\end{array}$ & $\begin{array}{c}\text { Without estimating } \\
\text { the radius }\end{array}$ & $\begin{array}{c}\text { With estimation of } \\
\text { the radius }\end{array}$ \\
\cline { 2 - 3 } & $\begin{array}{c}\text { Mean error } \\
\text { (standard deviation) }\end{array}$ & $\begin{array}{c}\text { Mean } \text { error } \\
\text { (standard deviation) }\end{array}$ \\
\hline $\begin{array}{c}\text { Points over the } \\
\text { whole of the circle }\end{array}$ & $\begin{array}{l}\mathbf{0 . 0 0 2 4} \\
(0.0018)\end{array}$ & $\begin{array}{l}\mathbf{0 . 0 0 2 4} \\
(0.0018)\end{array}$ \\
\hline $\begin{array}{c}\text { Points over } 1 / 4 \text { of } \\
\text { the circle }\end{array}$ & $\begin{array}{l}\mathbf{0 . 0 0 3 1} \\
(0.0025)\end{array}$ & $\begin{array}{l}\mathbf{0 . 0 1 4 3} \\
(0.0095)\end{array}$ \\
\hline
\end{tabular}

A shown in Table II, the estimate of the radius does not cause any errors as long as the points are equally distributed around the circle. In the actual case where the LIDAR has a field of view over a quarter of the pile, the error increases significantly. This method improves the estimate of the centre by more than fourfold.

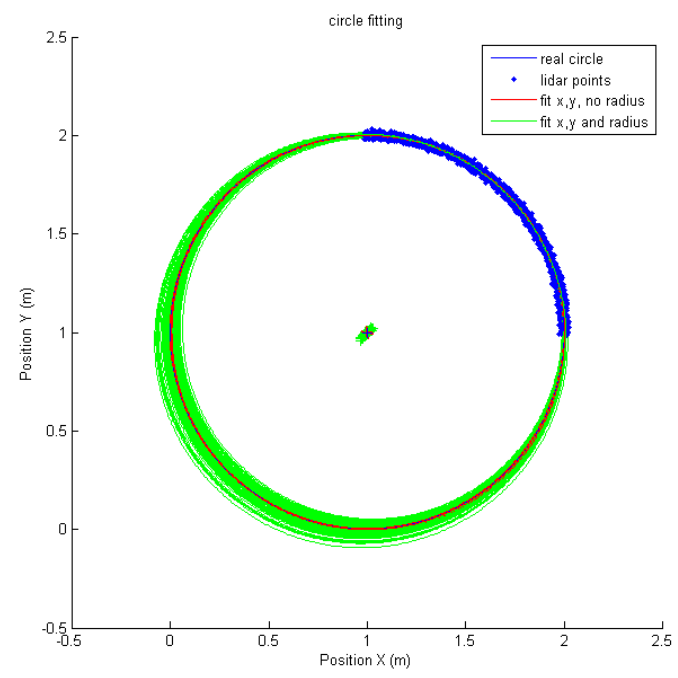

Figure 9 Estimate of the position of the circle when the measuring points are distributed around a $1 / 4$ of the circle only, 100 samples. The circles in 
green relate to the estimate of the position and the radius of the circle, thats in red when the radius is no longer estimated.

Figure 10 shows for 100 samples the distance errors with or without estimation of the radius. Deleting an unknown in minimizing the circular regression significantly increases the accuracy of the other two estimated parameters $(x, y)$.

Following the initial results, the overall algorithm in the docking phase takes place in two stages: the first is the initialisation phase where a complete estimate (position and radius of the wind turbine) is produced. A low-pass filter then extracts a filtered estimate of the radius. Once this value is sufficiently stable, it is kept as a constant. During the second phase, only the position of the centre of the wind turbine is estimated.

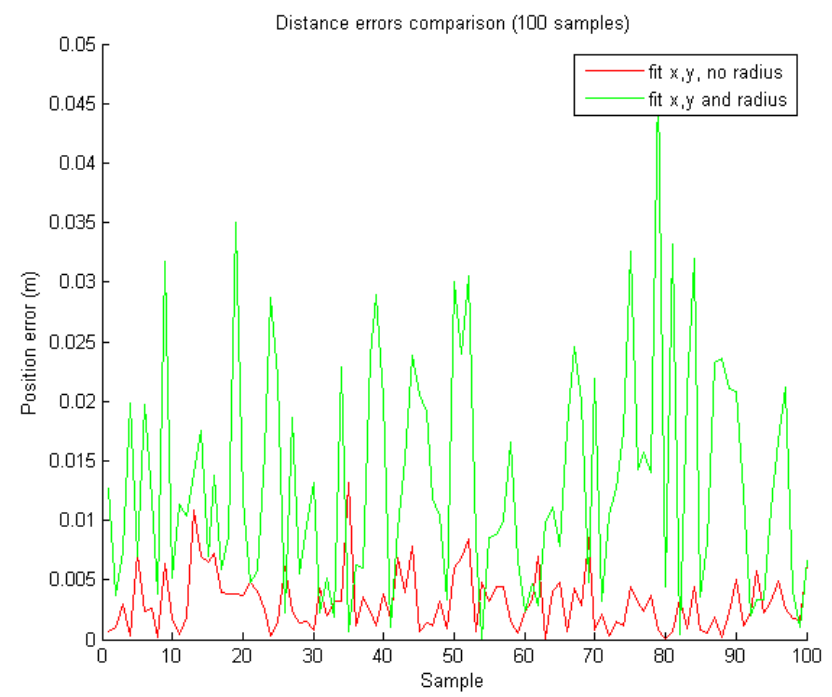

Figure 10 Distance error over 100 samples

In our application, the movements of the ship cause the LIDAR to tilt. The intersection of the plane formed by its sheet with the cylinder of the wind turbine will not therefore form a circle, but an ellipse which can be represented by the equation:

$\frac{\left(x-x_{0}\right)^{2}}{a^{2}}+\frac{\left(y-y_{0}\right)^{2}}{b^{2}}=1$

which requires five points to be sampled instead of three. However, as the positions of the foci vary according to the inclination of the LIDAR, it will not be possible to fix them as when estimating the radius. We have not selected this method and have preferred an approach which consists of projecting LIDAR points in a horizontal plane from attitude data provided by the inertial system.

\section{Evaluation with a $3 D$ simulator}

To evaluate the algorithm in realistic scenarios and in real time, we implemented a full simulation chain using a ProSivic simulator and RTMaps middleware. The ship is animated with the same sea movements as those used for evaluating the inertial systems (Figure 4). The gangway simulated is of the turret and telescopic ladder type (Figure 11).

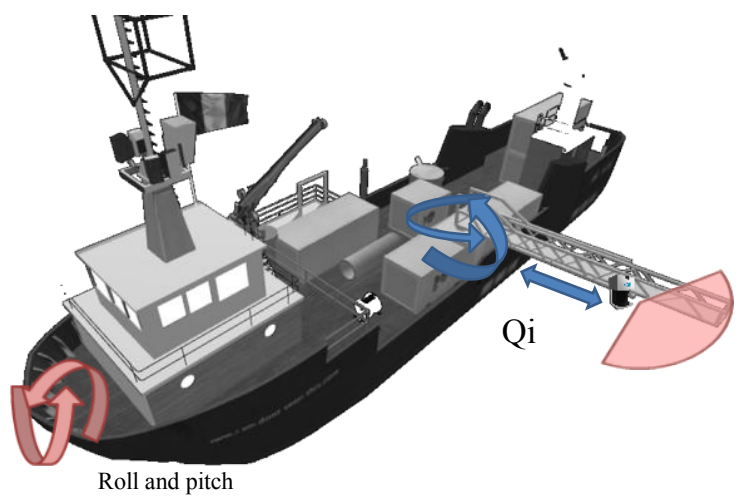

Figure 11 In the simulator, the ship's roll and pitch movements are measured by an inertial system, the Qi articular variables representing the actuators of the gangway and the LIDAR is positioned at the end of the fixed part of the gangway.

By using a more realistic 3D model of the wind turbine pile (presence of a ladder), we note that the measurement of the position of the centre of the wind turbine is upset, the LIDAR plane intersects a rung of the ladder. The best circle not longer corresponds to the wind turbine pile as numerous relevant points are hidden by the objects in front of the tube (Figure 12).

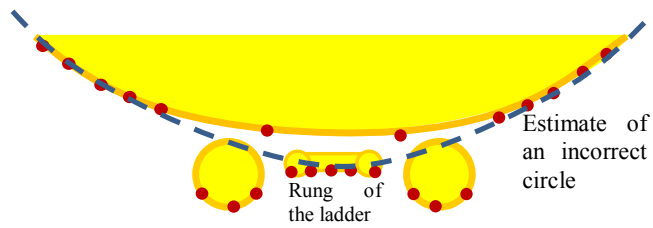

Figure 12 The ladder rung problem: estimate of an incorrect circle passing through a rung of the ladder, the pile being in its shadow.

A jump in the position of the centre occurs which will cause a major disturbance for the instrumentation and control system. The algorithm calculates the error in the least squares sense between the estimated circle and the LIDAR points selected by the Ransac. This value correctly distinguishes the incorrect estimates (Figure 13). A Kalman filter [9] is therefore employed to carry out 2D tracking of the position of the centre of the wind turbine [11]. The state vector to be estimated is made up of the position and speed of the centre of the wind turbine. For the transition between two successive states (eq. 3), we assume a constant speed and the position is integrated using the product of the speed with the sampling period $t_{s}$. This model ignores completely the underlying physical and nonlinear behavior of ship movements. Nevertheless, as the frequency of sensor updates is high $(40 \mathrm{~Hz})$, one can considerer the displacement between two measurements small enough to assume linear dynamics. 
The measurement equation (eq. 4) is entered with position data only.

$$
\begin{aligned}
& \text { State vector } x=\left[\begin{array}{l}
x \\
y \\
\dot{x} \\
\dot{y}
\end{array}\right] \\
& x_{k}=A x_{k-1}+w_{k} \text { where } A=\left[\begin{array}{llll}
1 & 0 & t_{s} & 0 \\
0 & 1 & 0 & t_{s} \\
0 & 0 & 1 & 0 \\
0 & 0 & 0 & 1
\end{array}\right]
\end{aligned}
$$

Measurement equation:

$$
z_{k}=H x_{k}+v_{k} \text { where } H=\left[\begin{array}{ll}
1 & 0 \\
0 & 1 \\
0 & 0 \\
0 & 0
\end{array}\right]
$$

The error between the estimated circle and the points selected by the Ransac will be used directly as noise $v_{k}$ in the measurement equation (4), which allows the filter to adjust the confidence between the model and the data from the Ransac.

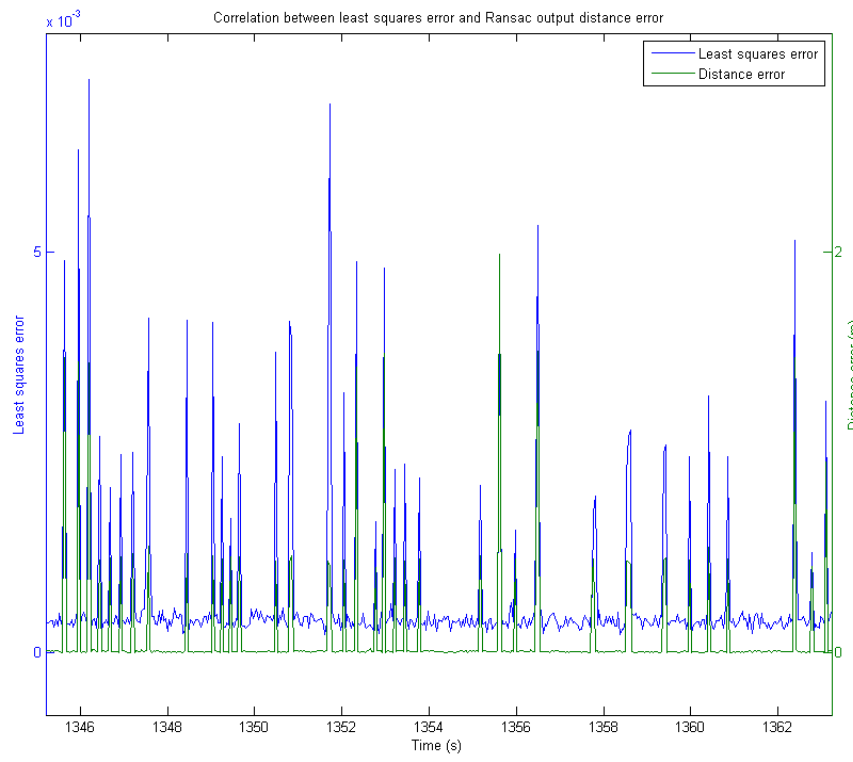

Figure 13 Correlation between the least squares error (blue) and the distance error at the output from the Ransac (green).

\section{OVERALL PERFORMANCES OF THE PERCEPTION CHAIN}

To analyse the performances of our model, we compared the results with and without the Kalman filter.

In Figure 14, we see that the Ransac produced foreign objects (due, amongst other things, to the ladder rungs) which are corrected with the Kalman filter as shown in Figure 15.

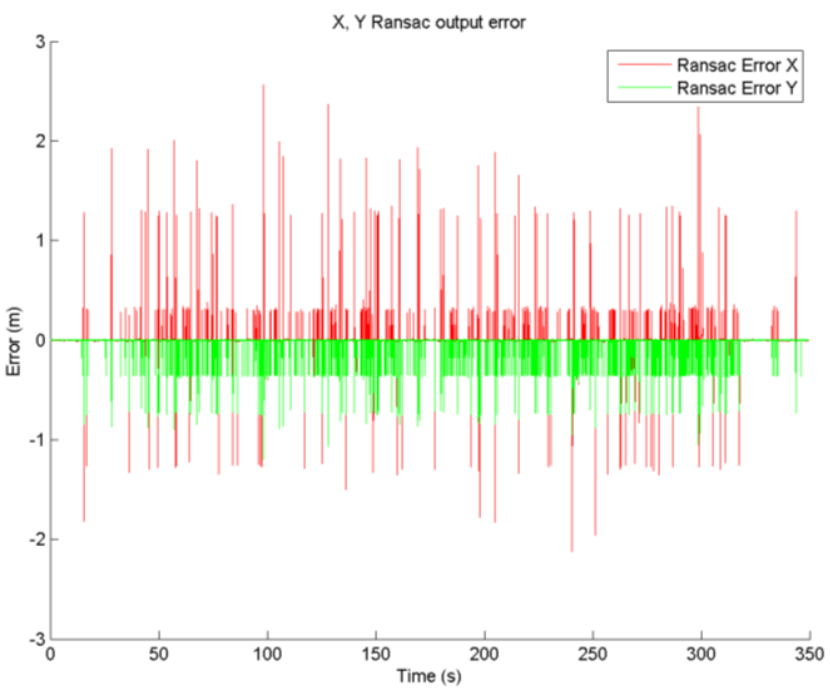

Figure 14 Positioning error at the output from the Ransac for X and Y: the error is major and incompatible with control of the gangway.

To facilitate the comparison, we calculated the norm of the distance error which represents the distance between the actual position of the wind turbine and the estimated centre.

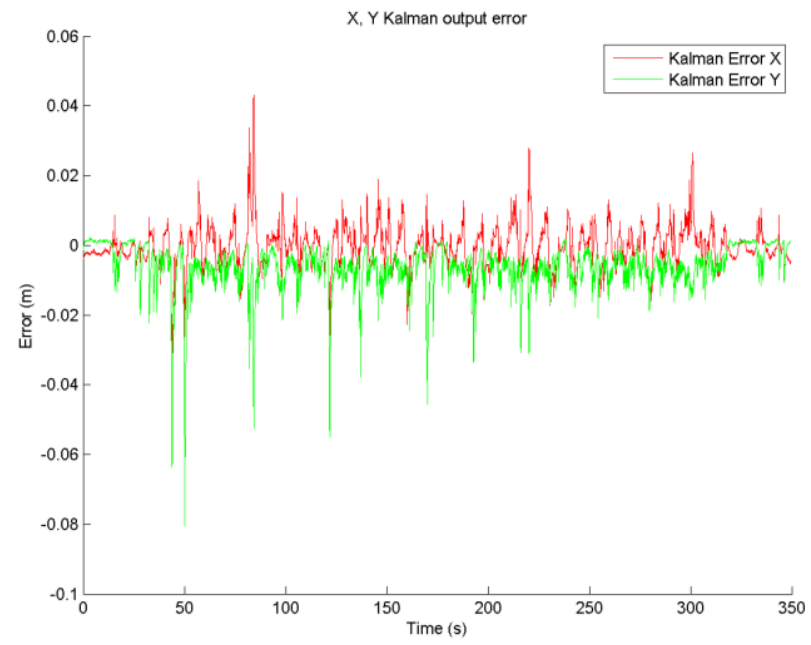

Figure 15 Positioning error at the output from the Kalman filter: the filter smooths the points by limiting the displacement speed of the centre of the wind turbine.

TABLE III COMPARISON OF ACCURACY ACCORDING TO THE SEA STATE

\begin{tabular}{|c|c|c|}
\hline $\begin{array}{c}\text { Distance } \\
\text { error in } \\
\text { meters }\end{array}$ & $\begin{array}{c}\text { Specific height 2.5 } \mathbf{m} \\
\text { Mean error } \\
\text { (standard deviation) }\end{array}$ & $\begin{array}{c}\text { Specific height 4m } \\
\text { Mean error } \\
\text { (standard deviation) }\end{array}$ \\
\hline Ransac & $\mathbf{0 . 0 6 3 4 7}$ & $\mathbf{0 . 0 6 9 1 5 3}$ \\
output & $(0.051236)$ & $\mathbf{( 0 . 0 5 9 9 5 6 )}$ \\
\hline Kalman & $\mathbf{0 . 0 0 8 0 8 5 1}$ & $\mathbf{0 . 0 0 8 8 7 1 3}$ \\
output & $(4.8942 \mathrm{e}-05)$ & $\mathbf{( 5 . 4 1 \mathrm { e } - 0 5 )}$ \\
\hline
\end{tabular}

Table III shows that the algorithms are not sensitive to the sea state, as that the amplitude and speed of the movements imparted have little effect on the accuracy of the measurements. For the rest of the study, we will use the sea state at a Specific Surge Height (Hs) of $2.5 \mathrm{~m}$, which corresponds to our application. 

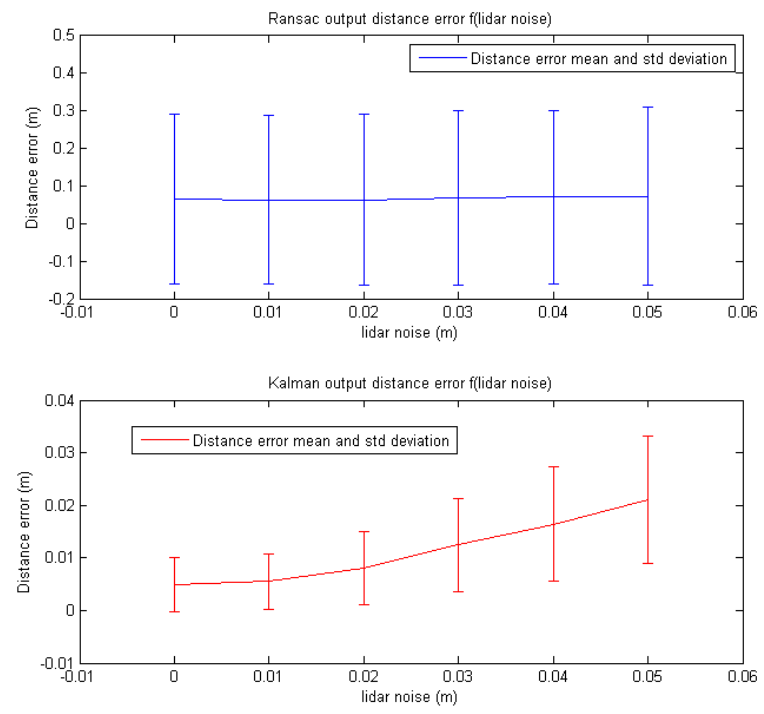

Figure 16 Distance error according to LIDAR noise: output from the Ransac in blue, output from the Kalman in red

Figure 16 represents the distance error as a function of the noise in the LIDAR measurements. The output from the Ransac is not affected by the LIDAR noise as the artefacts due to the problems of the ladder rungs are predominant (Figure 14). On the other hand, once the position data has been filtered by the Kalman, the LIDAR noise is found on the mean and standard deviation on output from the algorithm.

For our application (Hs $2.5 \mathrm{~m}$ ) and LIDAR noise of about $2 \mathrm{~cm}$, we obtain an average precision of about $8 \mathrm{~mm}$ positioning with a standard deviation of $7 \mathrm{~mm}$.

From the performance point of view, all the processing is carried out in real time from LIDAR data at $25 \mathrm{~Hz}$, using $6 \%$ of one of the cores of an Intel i7-2640M @ $2.8 \mathrm{GHz}$ with RTMaps middleware. A video showing our problem and the results obtained is available at the following address:

\section{http://www.youtube.com/watch?v=5yUvnkWEVDA}

\section{CONCLUSION}

By using a Ransac algorithm and a Kalman filter, we have been able to develop a wind turbine positioning algorithm which provides the accuracy necessary for safe disembarkation of personnel working on offshore wind turbines which is sufficiently robust to foreign objects. This positioning data will be used in controlling the kinematic chain of the gangway.

\section{ACKNOWLEDGEMENTS}

This study has been co-financed by the ADEME as part of the NAVALIS project and by ACEBI.

\section{BIBLIOGRAPHY}

[1] Ampelmann http://www.ampelmann.nl/products/

[2] OSBV Offshore solutions

[3] Uptime http://www.uptime.no/

[4] Momac http://www.momac-robotics.de/momac-Offshore-AccessSystem-MOTS.html

[5] Houlder http://houlderltd.com/

[6] Osbit http://www.osbitpower.com/t12_t18.html

[7] Arck Sirrah LS08 : http://www.arcksensor.com/?q=products/steel/sirrah/ls08

[8] Sick, Long range distance sensors DMT

[9] R.E. Kalman, "A New Approach to Linear Filtering and Prediction Problems", in Transactions of the ASME - Journal of Basic Engineering, vol 82,1960, p. 35-45

[10] D. Umbach \& K. N. Jones, «A Few Methods for Fitting Circles to Data », in IEEE Transactions on Instrumentation and Measurement, vol. $52, n^{\circ} 6,2003$, p. $1881-1885$

[11] R. Branko \& A Sanjeev \& G. Neil James, "Beyond the Kalman filter: Particle filters for tracking applications", in Artech House Publishers 2004, p89

[12] D. Gruntz, "Finding the Best Fit Circle", in The MathWorks Newsletter, vol. 1, 1990, p. 5

[13] M.A. Fischler, \& R.C. Bolles, "Random sample consensus : A paradigm for model fitting with applications to image analysis and automated cartography", in Communications of the ACM, vol. 24, 1981, p. 381-395

[14] A. Guignamard, "Ekinox, Test Report", SGB Systems 2013

[15] Chaumette, F., \& Hutchinson, S. "Visual servo control. I. Basic approaches" in Robotics \& Automation Magazine, 2006, IEEE, 13(4), p82-90.

[16] Chaumette, F., \& Hutchinson, S, "Visual servo control, Part II: Advanced approaches". IEEE Robotics and Automation Magazine, 2007 14(1), p109-118.

[17] The European offshore wind industry - key trends and statistics 2012, EWEA, janv. 2013

[18] Sick, "Sensors and solutions for ports, Higher efficiency and greater safety", 2007

[19] W. Khalil et J. Kleinfinger. A New Geometric Notation for Open and Closed Loop Robots. ICRA'86, pages 75-79, avril 1986 